\title{
Improvement of Coenzyme Q10 Production: Mutagenesis Induced by High Hydrostatic Pressure Treatment and Optimization of Fermentation Conditions
}

\author{
Yahong Yuan, Yuting Tian, and Tianli Yue \\ College of Food Science and Engineering, Northwest A\&F University, Yangling, Shaanxi 712100, China \\ Correspondence should be addressed to Tianli Yue, ytl6503@yahoo.com.cn
}

Received 19 March 2012; Revised 6 July 2012; Accepted 20 July 2012

Academic Editor: Andrei Surguchov

Copyright () 2012 Yahong Yuan et al. This is an open access article distributed under the Creative Commons Attribution License, which permits unrestricted use, distribution, and reproduction in any medium, provided the original work is properly cited.

\begin{abstract}
Coenzyme Q10 (CoQ10, ubiquinone), a potent antioxidative dietary supplement, was produced by submerged fermentation using Agrobacterium tumefaciens instead of chemical synthesis or solvent extraction. Agrobacterium tumefaciens 1.2554 was subjected to mutagenesis using a series of treatments including high hydrostatic pressure (HHP) treatment, UV irradiation, and diethyl sulfate (DES) treatment to obtain mutant strains showing higher CoQ10 production than wild-type strains. A mutant strain PK38 with four genetic markers was isolated: the specific CoQ10 content of the mutant strain increased by $52.83 \%$ compared with the original strain. Effects of carbon and nitrogen sources on CoQ10 production with PK38 were studied. Sucrose at concentration of $30 \mathrm{~g} / \mathrm{l}$ was tested as the best carbon source, and yeast extract at concentration of $30 \mathrm{~g} / \mathrm{l}$ supplemented with $10 \mathrm{~g} / \mathrm{l}$ of ammonium sulfate was identified to be the most favorable for CoQ10 production using PK38. Fed-batch culture strategy was then used for increasing production of CoQ10 in 5-1 fermentor. Using the exponential feeding fed-batch culture of sucrose, cell growth and CoQ10 formation were significantly improved. With this strategy, the final cell biomass, CoQ10 production, and specific CoQ10 production increased by $126.11,173.12$, and $22.76 \%$, respectively, compared to those of batch culture.
\end{abstract}

\section{Introduction}

Coenzyme Q10 (CoQ10), also known as ubiquinone or ubiquinone-10, occurs widely in animals, plants, and the cells of microorganisms. It plays a crucial role in generation of cellular energy and in free radical scavenging in the human body [1]. Accordingly, it has been used in therapeutic applications for several diseases such as heart disease [2], breast cancer [3], and Alzheimer's and Parkinson's diseases [4]. Moreover, CoQ10 has been used as a food supplement and cosmetic ingredient because of its various physiological functions. Extensive attempts have been made to increase CoQ10 production to meet growing demands for this product. To date, production of CoQ10 is produced by one of three methods: extraction from biological tissues [5], chemical synthesis [6], and microbial fermentation [7]. In the wake of recent environmental awareness, the first two methods became least desirable because of the inherent uses of solvents and chemicals in the process. Microbial fermentation, conversely, offers an environmentally benign option based on the enzymatic catalysis at the cellular level for CoQ10 assembly. Also, this approach is attractive to the industry because the process is easy to control and has a relatively low production cost $[8,9]$. Among all strains investigated so far, A. tumefaciens has been shown to be an excellent producer of CoQ10 [7, 10-13]. However, the yield of CoQ10 in liquid cultivation using the wild-type strain of A. tumefaciens remains limited because of its low specific CoQ10 content.

To increase the specific CoQ10 content of $A$. tumefaciens, further strain development by physical and chemical mutagenesis has been used to obtain high-CoQ10-producing mutants. Well-known mutagens such as ultraviolet radiation and diethyl sulfate (DES) have been tested. However, the chemicals used for these mutagenesis procedures are harmful to human health. It is desirable to find new mutagenic treatments to increase CoQ10 yield. 
In recent years, there were reports about high hydrostatic pressure (HHP) treatment that influenced the structure of genes and proteins in microorganisms [14-16]. There were also reports that HHP treatment in laboratory could cause beneficial mutagenesis to E. coli [17, 18], R. glutinis $[19,20]$, and G. xylinus [21]. Compared with traditional physical and chemical mutagenesis methods, HHP treatment as a mutagen could offer some advantages such as easier handling, savings in time and money, and negligible effects to the environment $[19,20]$. However, little is known related to the effectiveness of HHP treatment on improving the production of CoQ10 in microorganisms.

Carbon and nitrogen sources significantly affected cell growth and CoQ10 production [12]. Aside from the optimization of carbon and nitrogen sources, the use of fedbatch culture by controlling the nutrient feeding is one of the most popular methods to achieve high cell density of $E$. coli [22-24] and enhance the production of CoQ10 [11, 12]. Exponential feeding is a simple method that was widely employed for E. coli cultivation [23]. So far, there seem to be no published reports related to the CoQ10 production under exponential feeding fed-batch control.

In this study, HHP treatment was investigated as a new mutagenic treatment to increase the specific CoQ10 content of A. tumefaciens. A mutant strain PK38 was isolated using selection markers and the optimal carbon and nitrogen sources for CoQ10 production with PK38 were selected. A new exponential feeding strategy was proposed for improving CoQ10 production using PK38.

\section{Materials and Methods}

2.1. Microorganism and Culture Medium. The parental strain A. tumefaciens 1.2554 was purchased from China General Microbiological Culture Collection Center (CGMCC, Beijing, China). This strain was inoculated on mannitol agar slants, incubated for 2 days at $28^{\circ} \mathrm{C}$, and then stored at $4^{\circ} \mathrm{C}$.

All media were sterilized by autoclaving at $121^{\circ} \mathrm{C}$ for $20 \mathrm{~min}$ and were adjusted to $\mathrm{pH} 7.2$ before sterilization. The complete medium contained $5 \mathrm{~g} / \mathrm{L}$ glucose, $3 \mathrm{~g} / \mathrm{L}$ beef extract, $3 \mathrm{~g} / \mathrm{L}$ yeast extract, $10 \mathrm{~g} / \mathrm{L}$ peptone, and $0.2 \mathrm{~g} / \mathrm{L}$ $\mathrm{MgSO}_{4} \cdot 7 \mathrm{H}_{2} \mathrm{O}$. The selective medium was made by adding a certain amount of one of the following four substances: sodium azide, ethionine, daunomycin, or vitamin $\mathrm{K}_{3}$. The seed medium consisted of $10 \mathrm{~g} / \mathrm{L}$ glucose, $5 \mathrm{~g} / \mathrm{L}$ peptone, $5 \mathrm{~g} / \mathrm{L}$ yeast extract, and $5 \mathrm{~g} / \mathrm{L} \mathrm{NaCl}$. The basal fermentation medium contained $20 \mathrm{~g} / \mathrm{L}$ glucose, $10 \mathrm{~g} / \mathrm{L}$ peptone, $10 \mathrm{~g} / \mathrm{L}$ yeast extract, $0.5 \mathrm{~g} / \mathrm{L} \mathrm{K}_{2} \mathrm{HPO}_{4}, 0.5 \mathrm{~g} / \mathrm{L} \mathrm{KH}_{2} \mathrm{PO}_{4} 0.5 \mathrm{~g} / \mathrm{L}$, and $0.5 \mathrm{~g} / \mathrm{L} \mathrm{MgSO}_{4} \cdot 7 \mathrm{H}_{2} \mathrm{O}$.

2.2. Preparation of Cell Suspensions. One loop of bacterial cells grown overnight on a mannitol agar slant was inoculated to $250 \mathrm{~mL}$ Erlenmeyer flask containing $50 \mathrm{~mL}$ of a seed medium and incubated on a rotary shaker $(200 \mathrm{rpm})$ at $28^{\circ} \mathrm{C}$ for $24 \mathrm{~h}$. After the culture entered the log phase (about $18-24 \mathrm{~h}$ in this study), $20 \mathrm{~mL}$ culture broth was centrifuged under $4^{\circ} \mathrm{C}$ at $10,000 \mathrm{rpm}(21,000 \times \mathrm{g})$ for $10 \mathrm{~min}$ (PM180R, ALC International, Milan, Italy), washed twice with sterile physiological saline, and suspended in sterile $0.1 \mathrm{M}$ potassium phosphate buffer of $\mathrm{pH} 7.2$ (cells density $10^{6}-10^{7}$ cell $/ \mathrm{mL}$ ) for HHP treatment.

2.3. HHP Mutation. The cell suspension in potassium phosphate buffer was transferred aseptically into sterile polyethylene pouches and heat-sealed following the expulsion of air. The prepared pouches were placed into the HHP equipment, containing a 21 working pressure chamber (UHPF-750MP, Baotou Kefa New Type Hi-Tech Food Machine Limited Company, Baotou, China). HHP treatments at constant pressures from 100 to $400 \mathrm{MPa}$ with holding time (10 to $30 \mathrm{~min}$ ) were carried out at room temperature (about $25^{\circ} \mathrm{C}$ ) using castor oil as the pressure medium. Control samples were maintained at atmospheric pressure within the constant temperature housing during the experiment.

To assess loss of viability caused by the HHP treatment, untreated and treated cell suspensions were serially diluted in PBS and plated on the basal agar plates. Agar plates were incubated at $28^{\circ} \mathrm{C}$ for 2 days for colony counting. Inactivation was expressed as a logarithmic viability reduction $\log \left(N_{0} / N\right)$, with $N_{0}$ and $N$ representing the colony counts before and after treatment, respectively [25].

2.4. $U V+D E S$ Mutation. The cell suspension was spread onto a presterilized plate $(9 \mathrm{~cm}$ diameter), and a UV lamp $(254 \mathrm{~nm}, 30 \mathrm{~W})$ was used for the mutation by irradiating cells at a distance of $30 \mathrm{~cm}$ from the plate for $60 \mathrm{~s}$. After UV radiation treatment, the cell suspension was treated with $1 \%$ $(\mathrm{v} / \mathrm{v})$ DES for $20 \mathrm{~min}$. The results show that the frequency of positive mutant generation is $12 \%$.

2.5. Screening for High-CoQ10-Producing Mutant. After each treatment, cell suspensions were spread on the selective medium and incubated at $28^{\circ} \mathrm{C}$ for $48 \mathrm{~h}$. The selective medium contained L-ethionine $(500 \mathrm{mg} / \mathrm{L})$, daunomycin $(20 \mathrm{mg} / \mathrm{L})$, vitamin $\mathrm{K}_{3}(160 \mathrm{mg} / \mathrm{L})$, or sodium azide $(20 \mathrm{mg} / \mathrm{L})$. All these chemicals were purchased from Ding Guo Biological Technology Co., LTD (Beijing, China). The fast-growing, large, and single colony was transferred onto the selective medium plate and then incubated for $48 \mathrm{~h}$ at $28^{\circ} \mathrm{C}$. The slant was preserved at $4^{\circ} \mathrm{C}$.

For screening, each mutant was taken and used in fermentation, and the content of CoQ10 from each mutant was determined.

2.6. Fermentation. The seed culture was transferred into a stirred tank fermentor (BioFlo 110, New Brunswick, NJ, USA) with a working volume of 21 production medium. The temperature, agitation speed, and air flow rate during the culture were $28^{\circ} \mathrm{C}, 300 \mathrm{rpm}$, and $0.6 \mathrm{l} / \mathrm{min}$, respectively. The $\mathrm{pH}$ was controlled at $7.2 \pm 0.1$ by addition of $3 \mathrm{M} \mathrm{NaOH}$ or $2 \mathrm{M} \mathrm{HCl}$.

2.7. Analytical Methods. The cell mass concentration was determined using a calibration curve constructed by optical density at $620 \mathrm{~nm}$ and dry cell weight (DCW). The optical density at $620 \mathrm{~nm}$ was measured with a spectrophotometer 
TABLE 1: HHP treatments on mutation of A. tumefaciens.

\begin{tabular}{lcccc}
\hline Mutation & No. of strains $(N)$ & Positive mutant $(r \%)$ & Specific CoQ10 content $(\mathrm{mg} / \mathrm{g}$ DCW $)$ & Improvement $(r \%)$ \\
\hline $400 \mathrm{Mpa} / 10 \mathrm{~min}$ & 56 & 5 & 1.645 & 8.4 \\
$250 \mathrm{Mpa} / 20 \mathrm{~min}$ & 80 & 10 & 1.690 & 11.3 \\
$200 \mathrm{Mpa} / 30 \mathrm{~min}$ & 78 & 16 & 1.784 & 17.5 \\
\hline
\end{tabular}

(UV-2500, Shimadzu, Tokyo, Japan). The DCW was determined after the culture broth was centrifuged at $10,000 \mathrm{rpm}$ $(21,000 \times \mathrm{g})$ for $10 \mathrm{~min}$ under $4^{\circ} \mathrm{C}$ using an ultracentrifuge. Cell lysis and CoQ10 extraction conducted in this study were similar to that described by Tian et al. [26]. The extracted CoQ10 was dissolved in ethanol and applied to a highperformance liquid chromatography (HPLC) system (LC2010A, Shimadzu, Tokyo, Japan) with a Hypersil ODS C18 $(5 \mu \mathrm{m}, 4.6 \mathrm{~mm} \times 250 \mathrm{~mm}$, Germany) coupled with a UV detector (Waters 486). The column was eluted with ethanol and methanol $(9: 1, \mathrm{v} / \mathrm{v})$ at a flow rate of $1.0 \mathrm{~mL} / \mathrm{min}$, and a chromatogram was obtained by monitoring the absorbance at $275 \mathrm{~nm}$. With an authentic CoQ10 standard (Sigma Co., Shanghai, China), CoQ10 was identified according to retention time and quantified by using a calibration curve. The residual sugar was quantified by Fehiling's reaction.

2.8. Statistical Analysis. All analyses were performed in triplicate. The experimental results obtained were expressed as means \pm SD. Statistical analysis was performed using the SPSS package (version 11.5, SPSS Inc., Chicago, IL). Data were analyzed by analysis of variance $(P<0.05)$, and the means were separated by Duncan's multiple range test.

\section{Results and Discussion}

3.1. Effect of HHP Treatment on Lethal Rate and Mutation of A. tumefaciens. To determine the optimum mutagenic conditions by HHP treatment, cell suspensions of A. tumefaciens were subjected to different HHP treatments combining pressure with holding time at $25^{\circ} \mathrm{C}$. Figure 1 shows the death curve of $A$. tumefaciens with HHP treatment. The data revealed that HHP treatment had a significant effect on A. tumefaciens, a Gram-negative bacterium. In general, Gram-negative bacteria are less resistant than the Grampositive bacteria to HHP treatments [25]. In this study, the cell viability during HHP treatment decreased with the increase of processing pressure and holding time. Based on the curve (Figure 1), deactivation of cells occurred between 4.0 and $4.5 \log$ units at $200 \mathrm{MPa}$ for $30 \mathrm{~min}, 250 \mathrm{MPa}$ for $20 \mathrm{~min}$, or $400 \mathrm{MPa}$ for $10 \mathrm{~min}$. Under these three levels, the mortality of A. tumefaciens was close to $100 \%$ (data not shown). Therefore, these three levels were chosen for subsequent mutagenesis [21].

Table 1 shows the effect of HHP treatments on mutation of A. tumefaciens. It is evident that the HHP treatment, at $200 \mathrm{MPa}$ for $30 \mathrm{~min}$, is better than the other two treatments: $250 \mathrm{MPa}$ for $20 \mathrm{~min}$ and $400 \mathrm{MPa}$ for $10 \mathrm{~min}$. Positive mutations accounted for $16 \%$ of these mutants, and 12 strains had a specific CoQ10 content higher than that from

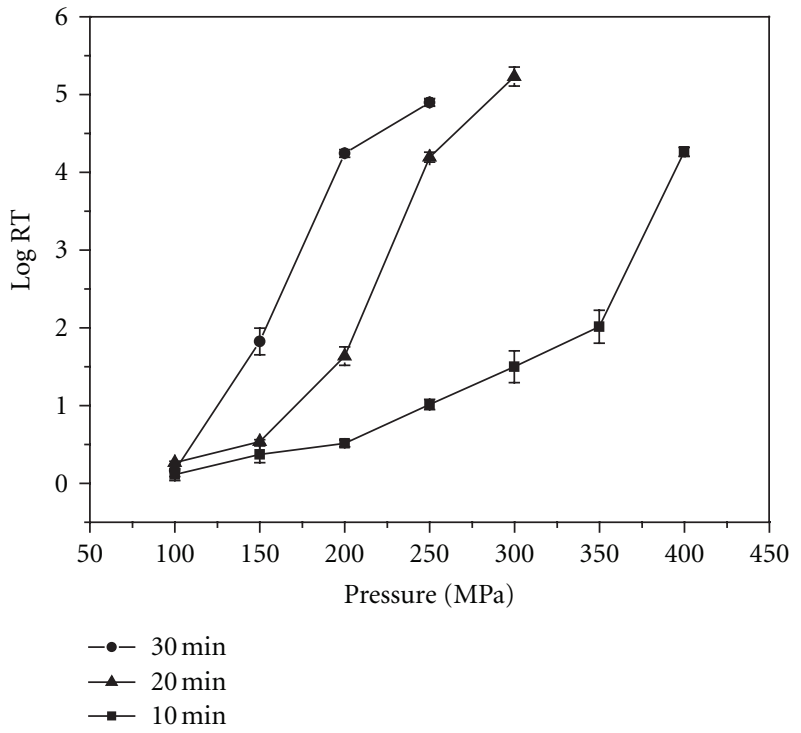

FIgURE 1: Death curve of $A$. tumefaciens caused by HHP treatment. Process temperature $25^{\circ} \mathrm{C} . \log \mathrm{RF}=\log \left(N_{0} / N\right)$. Data are shown as mean $\pm \mathrm{SD}(n=3)$.

the wild-type strain. Among those 12 strains, maximum specific CoQ10 content was achieved from the mutant PN07 with an approximate $17.5 \%$ increase compared with the wild-type strain. So the HHP treatment at $200 \mathrm{MPa}$ for 30 min was selected as the optimal condition for inducing mutation.

CoQ10 biosynthesis is typically composed of three parts: synthesis of a quinonoid ring, synthesis of decaprenyl diphosphate, and quinonoid ring modification [9]. The formation of each part is catalyzed by several enzymes. For example, decaprenyl diphosphate synthase (DPPS) can catalyze the synthesis of decaprenyl diphosphate, which appears to be a rate-limiting step and critical in CoQ10 production $[9,27]$. The present study found that HHP treatment can have beneficial mutagenic effects on A. tumefaciens for CoQ10 production, which agrees with the finding of Wu et al. [21] who found that the bacterial cellulose mutant $\mathrm{M}_{438}$ was obtained after HHP treatment at $250 \mathrm{MPa}$ for $15 \mathrm{~min}$. Wang et al. $[19,20]$ obtained the barotolerant mutant PR68 after five repeated cycles of HHP treatment at $300 \mathrm{MPa}$ for $12 \mathrm{~min}$. They found that the DNA segments of mutant PR68 were different from the original strain. Lauro et al. [28] reported that pressure triggered a stress response which activated distinct chaperones and DNA repair proteins. So the change of specific CoQ10 content of A. tumefaciens might occur at the gene level, and HHP treatment might have effects on the 


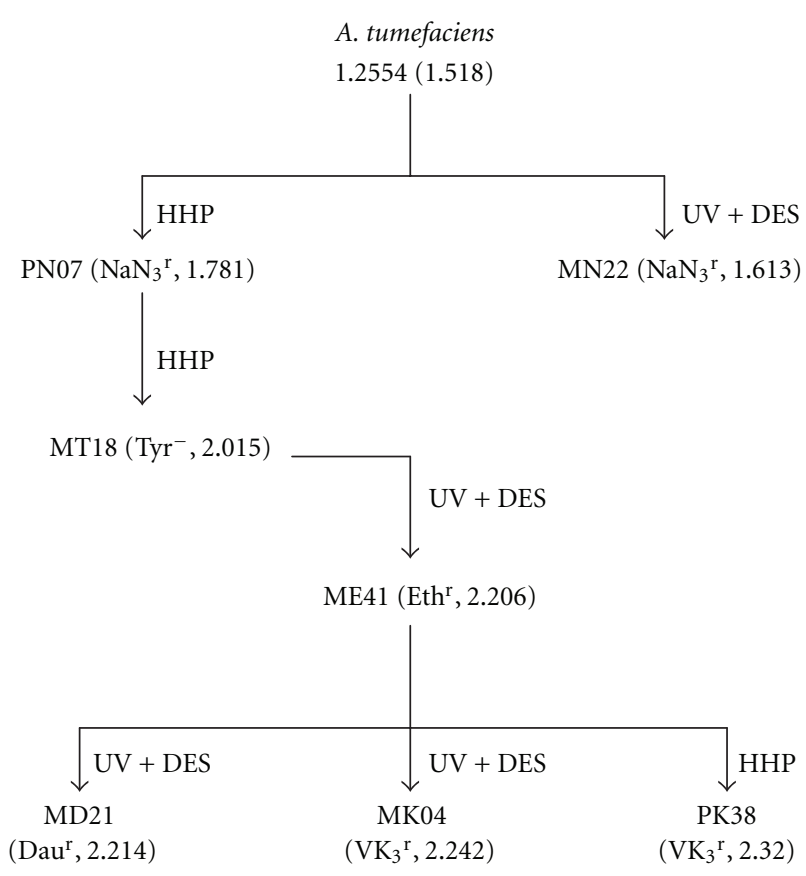

FIgURE 2: Genealogy of mutant strains derived from AT 1.2554. Mutation markers: $\mathrm{NaN}_{3}{ }^{\mathrm{r}}$, sodium azide $\left(\mathrm{NaN}_{3}\right)$ resistance; $\mathrm{Tyr}^{-}$, tyrosine auxotroph; $\mathrm{Eth}^{\mathrm{r}}$, ethionine resistance; Dau ${ }^{\mathrm{r}}$ daunomycin resistance; $\mathrm{VK}_{3}{ }^{\mathrm{r}}$, vitamin $\mathrm{K}_{3}$ resistance. All the mutants were induced by HHP or UV + DES treatment. The specific CoQ10 content ( $\mathrm{mg} / \mathrm{g}$ dry cell weight) was obtained in flask tests.

three enzymatic steps of CoQ10 biosynthesis. Study of these effects should be carried out in future research.

3.2. Screening A. tumefaciens. Random mutagenesis is an easy tool to use in achieving genetic and functional modifications of an organism. Using progressive stepwise mutagenesis-selection protocols and various mutagens with differing modes of action has been proven effective in increasing product yield [29]. To obtain a high-CoQ10producing strain from the wild type, mutagenesis was carried out by the HHP treatment (200 MPa, $30 \mathrm{~min}$ ) and UV+DES mutation. After each mutagenic treatment, the mutant strain was selected and assessed in shake flask cultures. The most promising strain was subjected to the next mutagenic treatment.

According to the general pathway of CoQ10 synthesis, two means of additional CoQ10 production are possible: the mutant could overcome growth inhibition during CoQ10 biosynthesis or its related metabolisms might overproduce CoQ10 [9]. These chemicals included L-ethionine (an analogue of L-methionine, which is a precursor for the methoxy moiety of CoQ10), daunomycin, and vitamin $\mathrm{K}_{3}$ (structural analogs of CoQ10). CoQ10 is an electron carrier in the respiration chain with antioxidant activity [30]. An electron flux inhibitor, such as sodium azide, can be used for screening the mutant, which can be resistant to this inhibitor because of high intracellular CoQ10 [9]. Moreover, tyrosine is located at a final branch point in the pathway of

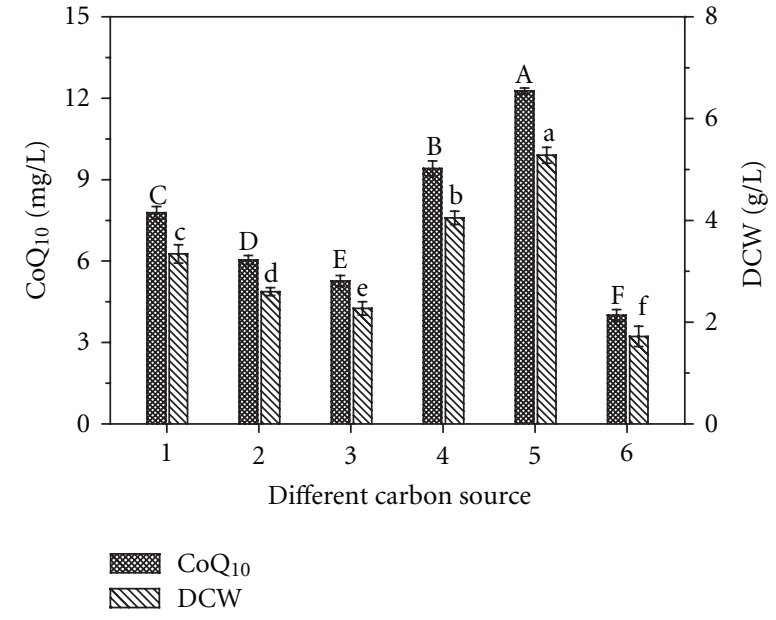

FIGURE 3: Effect of various carbon sources on the cell growth and CoQ10 production. Cells were cultivated in the test tube at $28^{\circ} \mathrm{C}$ for $72 \mathrm{~h}$. The carbon sources included glucose (1), fructose (2), lactose (3), maltose (4), sucrose (5), and xylose (6). Data are shown as mean $\pm \mathrm{SD}(n=3)$. Means with the same letter are not significantly different $(P<0.05)$.

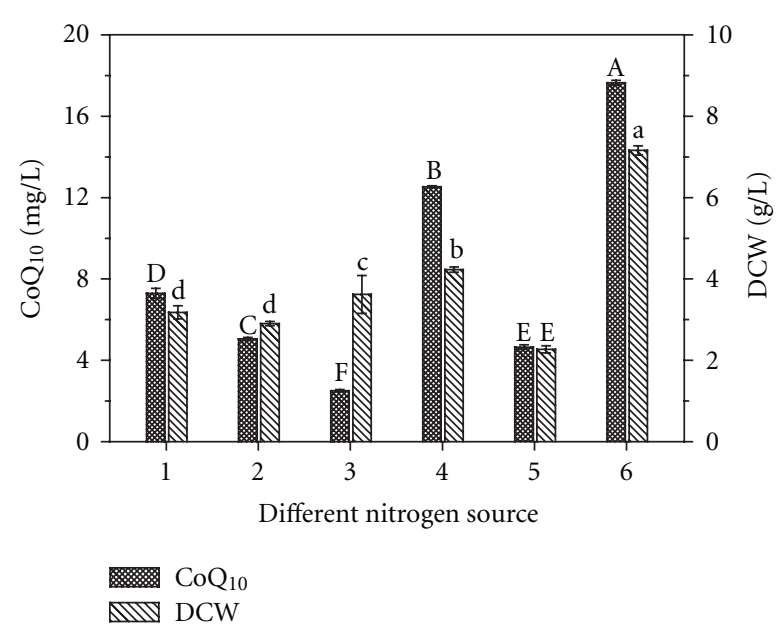

FIGURE 4: Effect of various nitrogen sources on the cell growth and CoQ10 production. Cells were cultivated in the test tube at $28^{\circ} \mathrm{C}$ for $72 \mathrm{~h}$. The nitrogen sources included yeast extract (1), peptone (2), tryptone (3), soytone (4), ammonium sulfate (5), and CSP (6). Data are shown as mean $\pm \mathrm{SD}(n=3)$. Means with the same letter are not significantly different $(P<0.05)$.

CoQ10 biosynthesis. So a tyrosine auxotrophic mutant might enhance CoQ10 production.

As Figure 2 shows, the mutant strains isolated with respective chemicals at each mutation step were tested for their CoQ10 production by flask culturing, and the best strain was used as the parent for successive mutations. Figure 2 also shows the methods and the maximal specific CoQ10 content for such mutants. Among those chemicals used for selecting a high producer, daunomycin had no significant effect on the CoQ10 content. Finally, the strain with the highest specific CoQ10 content, named PK38, was 


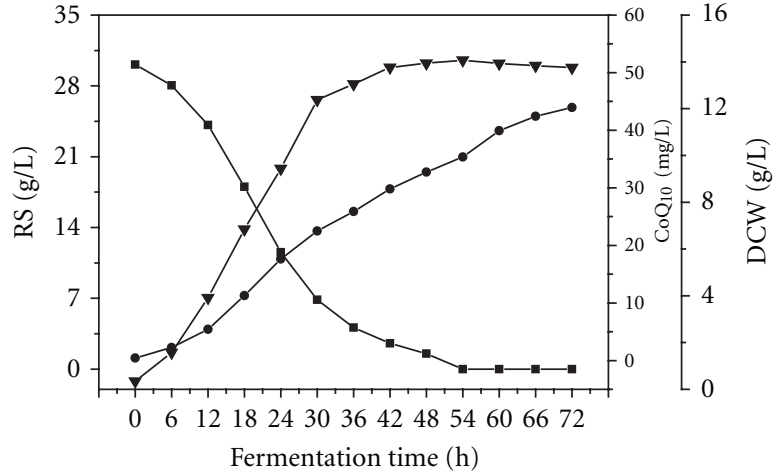

(a)

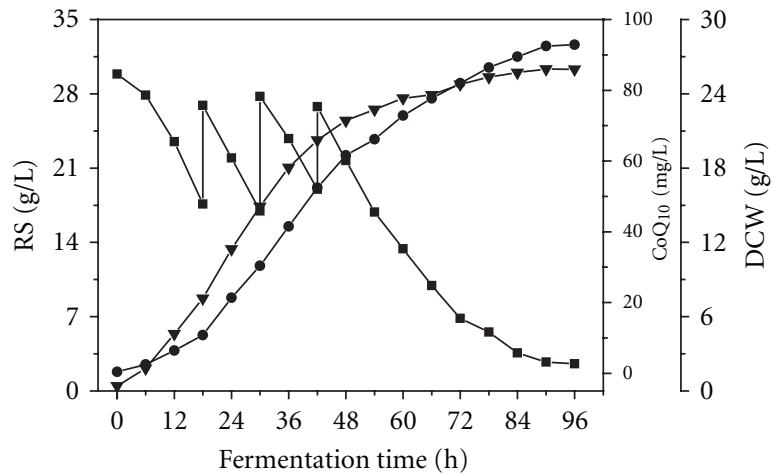

(b)

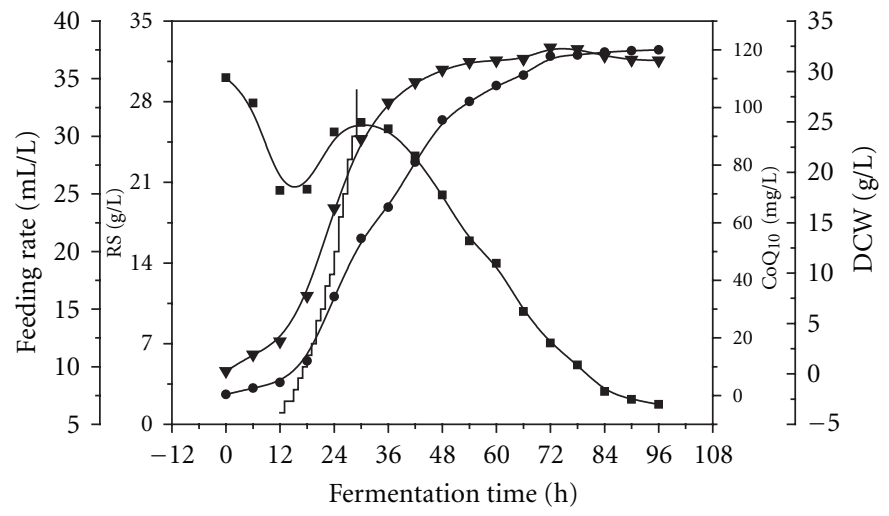

(c)

FIgURE 5: Profiles of DCW and CoQ10 production in batch (a), fed-batch (b), and exponential fed-batch (c) culture with PK38 in the 5-L fermentor at $28^{\circ} \mathrm{C}$; residual sugar (RS, filled square), CoQ10 (filled circle), DCW (filled inverted triangle).

TABLE 2: The experiment testing genetic stability and specific CoQ10 content of PK38.

\begin{tabular}{lccccc}
\hline Generations & 2 & 4 & 6 & 8 & 10 \\
\hline $\begin{array}{l}\text { Genetic markers } \\
\text { a }\end{array}$ & + & + & + & + & + \\
$\begin{array}{l}\text { Specific CoQ10 content } \\
(\mathrm{mg} / \mathrm{g})\end{array}$ & 2.321 & 2.320 & 2.318 & 2.319 & 2.318 \\
\hline
\end{tabular}

${ }^{\mathrm{a}}$ Genetic markers included $\mathrm{NaN}_{3}{ }^{\mathrm{r}}, \mathrm{Tyr}^{-}, \mathrm{Eth}^{\mathrm{r}}$, and $\mathrm{Vk}_{3}{ }^{\mathrm{r}}$.

obtained, containing about $52.83 \%$ higher specific CoQ10 content when compared with the original strain.

3.3. Stability of PK38 for CoQ10 Production. The mutant PK38 was selected, and its stability of producing specific CoQ10 content was investigated (Table 2). There was little fluctuation in specific CoQ10 content among 10 generations. Also, the genetic markers were stable. This illustrated PK38 strain has a good genetic stability and has the potential to be used for CoQ10 production.

3.4. Optimization of Carbon and Nitrogen Sources. To determine the optimal carbon and nitrogen source for CoQ10 production, cultures were prepared in $250 \mathrm{~mL}$ flasks containing $100 \mathrm{~mL}$ of fermentation medium with various carbon and nitrogen sources and incubated for $72 \mathrm{~h}$ on a rotary shaker (at $180 \mathrm{rpm})$ at $28^{\circ} \mathrm{C}$.

Figure 3 shows the effect of different carbon sources on PK38 growth and CoQ10 production. Among the various carbon sources (glucose, fructose, lactose, maltose, sucrose, and xylose), sucrose proved to be the best carbon source for the growth of PK38 with biomass reaching $5.28 \mathrm{~g} / \mathrm{L}$ after 72 hours of cultivation. Also, CoQ10 production was the highest when sucrose was used as a carbon source, reaching $12.27 \mathrm{mg} / \mathrm{L}$. These results are in agreement with the work conducted by $\mathrm{Ha}$ et al. [12]. To evaluate the effect of the initial concentrations of sucrose on PK38 growth and CoQ10 production, different concentrations of sucrose $(10,20,30,40$, and $50 \mathrm{~g} / \mathrm{L})$ were used. As Table 3 shows, CoQ10 production was highest at $30 \mathrm{~g} / \mathrm{L}$ of sucrose, reaching $14.88 \mathrm{mg} / \mathrm{L}$. So sucrose, at a concentration of $30 \mathrm{~g} / \mathrm{L}$, was selected as carbon source for CoQ10 production with PK38.

Figure 4 shows the effects of different nitrogen sources on biomass and CoQ10. The results demonstrate that crop steep powder (CSP) was more desirable than other nitrogen sources. The highest CoQ10 production $(17.65 \mathrm{mg} / \mathrm{L})$ was obtained with $20 \mathrm{~g} / \mathrm{L}$ of CSP, with the highest biomass at $7.16 \mathrm{~g} / \mathrm{L}$. CSP comprises the water soluble components of the crop, the composition of which is primarily amino acids, peptides, carbohydrates, and salts. CSPs are rich in nitrogen, 
TABLE 3: Effect of sucrose on DCW and CoQ10 production by PK38 with batch culture.

\begin{tabular}{lccc}
\hline Sucrose $(\mathrm{g} / \mathrm{L})$ & DCW $(\mathrm{g} / \mathrm{L})$ & CoQ10 concentration $(\mathrm{mg} / \mathrm{L})$ & Specific CoQ10 content $(\mathrm{mg} / \mathrm{g}$ DCW $)$ \\
\hline 10 & $4.11+0.065^{\mathrm{d}}$ & $9.55+0.196^{\mathrm{d}}$ & $2.325+0.037^{\mathrm{a}}$ \\
20 & $5.28+0.157^{\mathrm{b}}$ & $12.27+0.110^{\mathrm{b}}$ & $2.322+0.029^{\mathrm{a}}$ \\
30 & $6.40+0.161^{\mathrm{a}}$ & $14.88+0.172^{\mathrm{a}}$ & $2.326+0.069^{\mathrm{a}}$ \\
40 & $4.90+0.181^{\mathrm{c}}$ & $11.40+0.284^{\mathrm{c}}$ & $2.324+0.101^{\mathrm{a}}$ \\
50 & $4.12+0.148^{\mathrm{d}}$ & $9.56+0.056^{\mathrm{d}}$ & $2.320+0.019^{\mathrm{a}}$ \\
\hline
\end{tabular}

Data are shown as mean \pm SD $(n=3)$. Means with the same letter are not significantly different as indicated by Duncan's multiple range test $(P<0.05)$.

vitamins, and other growth stimulating compounds. Therefore, CSP was used as an ingredient in media for cultivation of microorganisms. Different concentrations of CSP $(10,20$, 30,40 , and $50 \mathrm{~g} / \mathrm{L}$ ) were used to evaluate the effect of the initial concentrations of CSP on PK38 growth and CoQ10 production. As Table 4 shows, CoQ10 production was the highest with $30 \mathrm{~g} / \mathrm{L}$ of sucrose, reaching $18.92 \mathrm{mg} / \mathrm{L}$. Ammonium may also have effects on CoQ10 synthesis. Knowles and Redfearn [31] found that the cells of Azotobacter vinelandii grown on ammonium medium produced comparatively high concentrations of CoQ10. Obviously, the complex nitrogen source (CSP + ammonium sulfate) was more desirable than single nitrogen sources (Table 5). CoQ10 production reached $20.62 \mathrm{mg} / \mathrm{L}$ with $30 \mathrm{~g} / \mathrm{L} \mathrm{CSP}$ and $10 \mathrm{~g} / \mathrm{L}$ ammonium sulfate in the production medium.

3.5. Fed-Batch CoQ10 Fermentation in 5-l Fermentor. Figure 5(a) shows the batch profile of DCW and CoQ10 production with the mutant PK38 in the 5-1 fermentor under the optimal carbon and nitrogen sources. During the batch fermentation of PK38, cell aggregation was observed after incubation, and after $42 \mathrm{~h}$, the cells were not grown further. The final yield of CoQ10 reached $43.94 \mathrm{mg} / \mathrm{L}$, which was significantly higher than that reached in the flask culture $(20.62 \mathrm{mg} / \mathrm{L})$, indicating that the low constant agitation $(300 \mathrm{rpm})$ provided in the 5 -1 fermentor might have enhanced cell-substrate contact [32], leading to the increase in CoQ10 productivity. The final biomass of PK reached $13.75 \mathrm{~g} / \mathrm{L}$, which was almost 2 times that obtained in the flask culture $(7.86 \mathrm{~g} / \mathrm{mL})$. This indicates that the specific CoQ10 content was $3.196 \mathrm{mg} / \mathrm{g}-\mathrm{DCW}$, which is much higher than that achieved in the flask culture $(2.624 \mathrm{mg} / \mathrm{g}-\mathrm{DCW})$.

As shown in the batch fermentation, CoQ10 production is mainly dependent on cell growth. A fed-batch fermentation of PK38 was carried out to get a high cell density and to increase more CoQ10 accumulation. When the residual sugar concentration of the broth dropped to about $17.5 \mathrm{~g} / \mathrm{L}$, 1001 of a sucrose solution (30\%) was fed to the 51 fermentor. As Figure 5(b) shows, sucrose feed was performed at 18, 30, and $40 \mathrm{~h}$, respectively. The feed strategy was designed so the residual sugar was kept at a concentration of $17-28 \mathrm{~g} / \mathrm{L}$. The feeding profile was found to be optimum, by maintaining a higher concentration of the residual sugar in the broth during the log phase of PK38. As a result, the cell density increased to $25.99 \mathrm{~g} / \mathrm{L}$, which was almost twice the amount obtained in the batch fermentation. Specifically, the final CoQ10 production reached $92.87 \mathrm{mg} / \mathrm{L}$ in $96 \mathrm{~h}$ of incubation,
TABLE 4: Effect of CSP on DCW and CoQ10 production by PK38 with batch culture.

\begin{tabular}{lccc}
\hline $\begin{array}{l}\text { CSP } \\
(\mathrm{g} / \mathrm{L})\end{array}$ & DCW $(\mathrm{g} / \mathrm{L})$ & $\begin{array}{c}\text { CoQ10 } \\
\text { production } \\
(\mathrm{mg} / \mathrm{L})\end{array}$ & $\begin{array}{c}\text { Specific CoQ10 } \\
\text { content } \\
(\mathrm{mg} / \mathrm{g}-\mathrm{DCW})\end{array}$ \\
\hline 10 & $6.67+0.061^{\mathrm{c}}$ & $15.67+0.080^{\mathrm{d}}$ & $2.351+0.016^{\mathrm{c}}$ \\
20 & $7.16+0.116^{\mathrm{b}}$ & $17.65+0.120^{\mathrm{b}}$ & $2.466+0.017^{\mathrm{b}}$ \\
30 & $7.46+0.095^{\mathrm{a}}$ & $18.92+0.146^{\mathrm{a}}$ & $2.536+0.047^{\mathrm{a}}$ \\
40 & $7.07+0.080^{\mathrm{b}}$ & $16.60+0.062^{\mathrm{c}}$ & $2.347+0.035^{\mathrm{c}}$ \\
50 & $7.62+0.038^{\mathrm{a}}$ & $16.81+0.182^{\mathrm{c}}$ & $2.207+0.022^{\mathrm{d}}$ \\
\hline
\end{tabular}

Data are shown as mean $\pm \mathrm{SD}(n=3)$. Means with the same letter are not significantly different as indicated by Duncan's multiple range test $(P<$ 0.05).

which was significantly higher than the batch operation. This demonstrates that the specific CoQ10 content achieved $3.575 \mathrm{mg} / \mathrm{g}$-DCW, which is much higher than that achieved in the batch fermentation.

In general, microorganisms will grow exponentially under the optimal condition. If the feed rate of the substrate is increased in proportion to the exponential growth rate, it is possible to maintain a high rate of cell growth for a long time [33]. Also, exponential feeding can limit the negative effect on the cell growth exerted by the sudden increase of sucrose. Figure 5(c) shows the profiles of DCW and CoQ10 production with the mutant PK38 in the 5-1 fermentor under the exponential feeding fed-batch control. The sucrose feed started from $12 \mathrm{~h}$ when the residual sugar concentration in the broth dropped to $21 \mathrm{~g} / \mathrm{L}$. The sucrose solution (30\%) flow rate profile was established in the equation described by Martínez et al. [34]. CoQ10 production increased quickly after $18 \mathrm{~h}$ of incubation, and the final yield reached $120.01 \mathrm{mg} / \mathrm{L}$. The production of CoQ10 was proportional to cell growth, and the final biomass obtained was $31.09 \mathrm{~g} / \mathrm{L}$. Also, the exponential feeding fed-batch culture resulted in the highest specific CoQ10 content within the cell biomass, reaching $3.860 \mathrm{mg} / \mathrm{g}$, superior to that of the aforementioned two cultures.

\section{Conclusion}

This work demonstrates that the use of HHP could be a promising approach for mutagenesis to a CoQ10 producer A. tumefaciens strain. A mutant strain PK38 was obtained by HHP treatment: the intracellular CoQ10 content of this 
TABLE 5: Effect of complex nitrogen sources on DCW and CoQ10 production by PK38 with batch culture.

\begin{tabular}{|c|c|c|c|}
\hline $\mathrm{CSP}+\left(\mathrm{NH}_{4}\right)_{2} \mathrm{SO}_{4}(\mathrm{~g} / \mathrm{L})$ & DCW (g/L) & CoQ10 production (mg/L) & Specific CoQ10 content (mg/g-DCW) \\
\hline $20+0$ & $7.16+0.116^{\mathrm{d}}$ & $17.65+0.098^{\mathrm{d}}$ & $2.466+0.017^{c}$ \\
\hline $20+5$ & $6.73+0.139^{f}$ & $16.17+0.091^{f}$ & $2.403+0.010^{c}$ \\
\hline $20+10$ & $6.92+0.097^{\mathrm{e}}$ & $17.08+0.082^{\mathrm{e}}$ & $2.467+0.027^{c}$ \\
\hline $20+15$ & $7.13+0.067^{\mathrm{d}}$ & $17.60+0.115^{\mathrm{d}}$ & $2.469+0.031^{\mathrm{c}}$ \\
\hline $30+0$ & $7.46+0.095^{c}$ & $18.92+0.146^{\mathrm{c}}$ & $2.536+0.047^{\mathrm{b}}$ \\
\hline $30+5$ & $7.65+0.107^{b}$ & $19.40+0.284^{\mathrm{b}}$ & $2.537+0.068^{\mathrm{b}}$ \\
\hline $30+10$ & $7.86+0.090^{\mathrm{a}}$ & $20.62+0.121^{\mathrm{a}}$ & $2.624+0.032^{\mathrm{a}}$ \\
\hline $30+15$ & $7.60+0.512^{b}$ & $18.54+0.085^{c}$ & $2.439+0.162^{c}$ \\
\hline
\end{tabular}

Data are shown as mean $\pm \mathrm{SD}(n=3)$. Means with the same letter are not significantly different as indicated by Duncan's multiple range test $(P<0.05)$.

strain increased by $52.83 \%$ when compared to the wildtype strain. Even though the mechanism of HHP-induced mutagenesis is not clear, HHP treatment might affect the three enzymatic steps of CoQ10 biosynthesis. Sucrose was the best carbon source, and CSP and ammonium sulfate were the optimal nitrogen sources for CoQ10 production with PK38. Fed-batch culture could significantly improve cell growth and CoQ10 production. By the exponential feeding strategy, the cell biomass and CoQ10 production increased 126.11 and $173.12 \%$, much higher than those obtained in the batch culture. There may be opportunities for further enhancement of the CoQ10 production in this species.

\section{Authors' Contribution}

Y. Yuan and Y. Tian contributed equally to this work.

\section{Acknowledgments}

The research was supported by China State "12th FiveYear Plan" scientific and technological support schemes (2012BAK17B06, 2012BAD31B01); National Natural Science Foundation of China (31071550, 31171721); Special Major Science and Technology Project in Shaanxi Province (2006 KZ09-G1); New Century Talent Plan of the Ministry of Education (2005); Beyond Plan of the Ministry of Agriculture (2005-4).

\section{References}

[1] L. Ernster and G. Dallner, "Biochemical, physiological and medical aspects of ubiquinone function," Biochimica et Biophysica Acta, vol. 1271, no. 1, pp. 195-204, 1995.

[2] R. B. Singh, M. A. Niaz, S. S. Rastogi, and S. P. Verma, "Coenzyme Q10 and its role in heart disease," Journal of Clinical Biochemistry and Nutrition, vol. 26, no. 2, pp. 109-118, 1999.

[3] O. Portakal, O. Ozkaya, M. E. Inal, B. Bozan, M. Koşan, and I. Sayek, "Coenzyme Q10 concentrations and antioxidant status in tissues of breast cancer patients," Clinical Biochemistry, vol. 33, no. 4, pp. 279-284, 2000.

[4] M. F. Beal, "Mitochondrial dysfunction and oxidative damage in Alzheimer's and Parkinson's diseases and coenzyme Q10 as a potential treatment," Journal of Bioenergetics and Biomembranes, vol. 36, no. 4, pp. 381-386, 2004.
[5] S. Laplante, N. Souchet, and P. Bryl, "Comparison of lowtemperature processes for oil and coenzyme Q10 extraction from mackerel and herring," European Journal of Lipid Science and Technology, vol. 111, no. 2, pp. 135-141, 2009.

[6] I. Ehud and E. Doron, "Total synthesis of polyprenoid natural products via $\mathrm{Pd}(\mathrm{O})$-catalyzed oligomerizations," Pure and Applied Chemistry, vol. 60, pp. 89-98, 1988.

[7] H. Yoshida, Y. Kotani, K. Ochiai, and K. Araki, "Production of ubiquinone-10 using bacteria," Journal of General and Applied Microbiology, vol. 44, no. 1, pp. 19-26, 1998.

[8] C. P. Cluis, A. M. Burja, and V. J. J. Martin, "Current prospects for the production of coenzyme Q10 in microbes," Trends in Biotechnology, vol. 25, no. 11, pp. 514-521, 2007.

[9] J. H. Choi, Y. W. Ryu, and J. H. Seo, "Biotechnological production and applications of coenzyme Q10," Applied Microbiology and Biotechnology, vol. 68, no. 1, pp. 9-15, 2005.

[10] G. S. Choi, Y. S. Kim, J. H. Seo, and Y. W. Ryu, "Restricted electron flux increases coenzyme Q10 production in Agrobacterium tumefaciens ATCC4452," Process Biochemistry, vol. 40, no. 10, pp. 3225-3229, 2005.

[11] S. B. Gu, J. M. Yao, Q. P. Yuan, P. J. Xue, Z. M. Zheng, and Z. L. Yu, "Kinetics of Agrobacterium tumefaciens ubiquinone10 batch production," Process Biochemistry, vol. 41, no. 8, pp. 1908-1912, 2006.

[12] S. J. Ha, S. Y. Kim, J. H. Seo, D. K. Oh, and J. K. Lee, "Optimization of culture conditions and scale-up to pilot and plant scales for coenzyme Q10 production by Agrobacterium tumefaciens," Applied Microbiology and Biotechnology, vol. 74, no. 5, pp. 974-980, 2007.

[13] S. J. Ha, S. Y. Kim, J. H. Seo, W. I. Sim, H. J. Moon, and J. K. Lee, "Lactate increases coenzyme Q10 production by Agrobacterium tumefaciens," World Journal of Microbiology and Biotechnology, vol. 24, no. 6, pp. 887-890, 2008.

[14] D. H. Bartlett, C. Kato, and K. Horikoshi, "High pressure influences on gene and protein expression," Research in Microbiology, vol. 146, no. 8, pp. 697-706, 1995.

[15] D. H. Bartlett, "Pressure effects on in vivo microbial processes," Biochimica et Biophysica Acta, vol. 1595, no. 1-2, pp. 367-381, 2002.

[16] P. M. B. Fernandes, "How does yeast respond to pressure?" Brazilian Journal of Medical and Biological Research, vol. 38, no. 8, pp. 1239-1245, 2005.

[17] K. J. A. Hauben, D. H. Bartlett, C. C. F. Soontjens, K. Cornelis, E. Y. Wuytack, and C. W. Michiels, "Escherichia coli mutants resistant to inactivation by high hydrostatic pressure," Applied and Environmental Microbiology, vol. 63, no. 3, pp. 945-950, 1997. 
[18] X. Gao, J. Li, and K. C. Ruan, "Barotolerant E. coli induced by high hydrostatic pressure," Acta Biochimica et Biophysica Sinica, vol. 33, no. 1, pp. 77-81, 2001.

[19] S. L. Wang, J. S. Sun, B. Z. Han, and X. Z. Wu, "Optimization of $\beta$-carotene production by Rhodotorula glutinis using high hydrostatic pressure and response surface methodology," Journal of Food Science, vol. 72, no. 8, pp. M325-M329, 2007.

[20] S. L. Wang, D. J. Chen, B. W. Deng, and X. Z. Wu, "Effects of high hydrostatic pressure on the growth and $\beta$-carotene production of Rhodotorula glutinis," Yeast, vol. 25, no. 4, pp. 251-257, 2008.

[21] R. Q. Wu, Z. X. Li, J. P. Yang, X. H. Xing, D. Y. Shao, and K. L. Xing, "Mutagenesis induced by high hydrostatic pressure treatment: a useful method to improve the bacterial cellulose yield of a Gluconoacetobacter xylinus strain," Cellulose, vol. 17, no. 2, pp. 399-405, 2010.

[22] Y. Wang, S. L. Wu, W. S. Hancock et al., "Proteomic profiling of Escherichia coli proteins under high cell density fed-batch cultivation with overexpression of phosphogluconolactonase," Biotechnology Progress, vol. 21, no. 5, pp. 1401-1411, 2005.

[23] B. S. Kim, S. C. Lee, S. Y. Lee, Y. K. Chang, and H. N. Chang, "High cell density fed-batch cultivation of Escherichia coli using exponential feeding combined with $\mathrm{pH}$-stat," Bioprocess and Biosystems Engineering, vol. 26, no. 3, pp. 147-150, 2004.

[24] D. J. Korz, U. Rinas, K. Hellmuth, E. A. Sanders, and W. D. Deckwer, "Simple fed-batch technique for high cell density cultivation of Escherichia coli," Journal of Biotechnology, vol. 39, no. 1, pp. 59-65, 1995.

[25] E. Y. Wuytack, A. M. J. Diels, and C. W. Michiels, "Bacterial inactivation by high-pressure homogenisation and high hydrostatic pressure," International Journal of Food Microbiology, vol. 77, no. 3, pp. 205-212, 2002.

[26] Y. Tian, T. Yue, J. Pei, Y. Yuan, J. Li, and Y. Martin Lo, "Effects of cell lysis treatments on the yield of coenzyme Q10 following Agrobacterium tumefaciens fermentation," Food Science and Technology International, vol. 16, no. 2, pp. 195-203, 2010.

[27] H. S. Zahiri, K. A. Noghabi, and Y. C. Shin, "Biochemical characterization of the decaprenyl diphosphate synthase of Rhodobacter sphaeroides for coenzyme Q10 production," Applied Microbiology and Biotechnology, vol. 73, no. 4, pp. 796806, 2006.

[28] F. M. Lauro, K. Tran, A. Vezzi, N. Vitulo, G. Valle, and D. H. Bartlett, "Large-scale transposon mutagenesis of Photobacterium profundum SS9 reveals new genetic loci important for growth at low temperature and high pressure," Journal of Bacteriology, vol. 190, no. 5, pp. 1699-1709, 2008.

[29] M. Chandra, A. Kalra, N. S. Sangwan, S. S. Gaurav, M. P. Darokar, and R. S. Sangwan, "Development of a mutant of Trichoderma citrinoviride for enhanced production of cellulases," Bioresource Technology, vol. 100, no. 4, pp. 16591662, 2009.

[30] M. Kawamukai, "Biosynthesis, bioproduction and novel roles of ubiquinone," Journal of Bioscience and Bioengineering, vol. 94, no. 6, pp. 511-517, 2002.

[31] C. J. Knowles and E. R. Redfearn, "The effect of combinednitrogen sources on the synthesis and function of the electron transport system of Azotobacter vinelandii," Biochimica et Biophysica Acta, vol. 162, no. 3, pp. 348-355, 1968.

[32] Y. M. Lo, C. H. Hsu, S. T. Yang, and D. B. Min, "Oxygen transfer characteristics of a centrifugal, packed-bed reactor during viscous xanthan fermentation," Bioprocess and Biosystems Engineering, vol. 24, no. 3, pp. 187-193, 2001.
[33] T. Yamanè and S. Shimizu, Fed-Batch Techniques in Microbial Processes, Springer, Berlin, Germany, 1984.

[34] A. Martínez, O. T. Ramírez, and F. Valle, "Effect of growth rate on the production of $\beta$-galactosidase from Escherichia coli in Bacillus subtilis using glucose-limited exponentially fedbatch cultures," Enzyme and Microbial Technology, vol. 22, no. 6, pp. 520-526, 1998. 

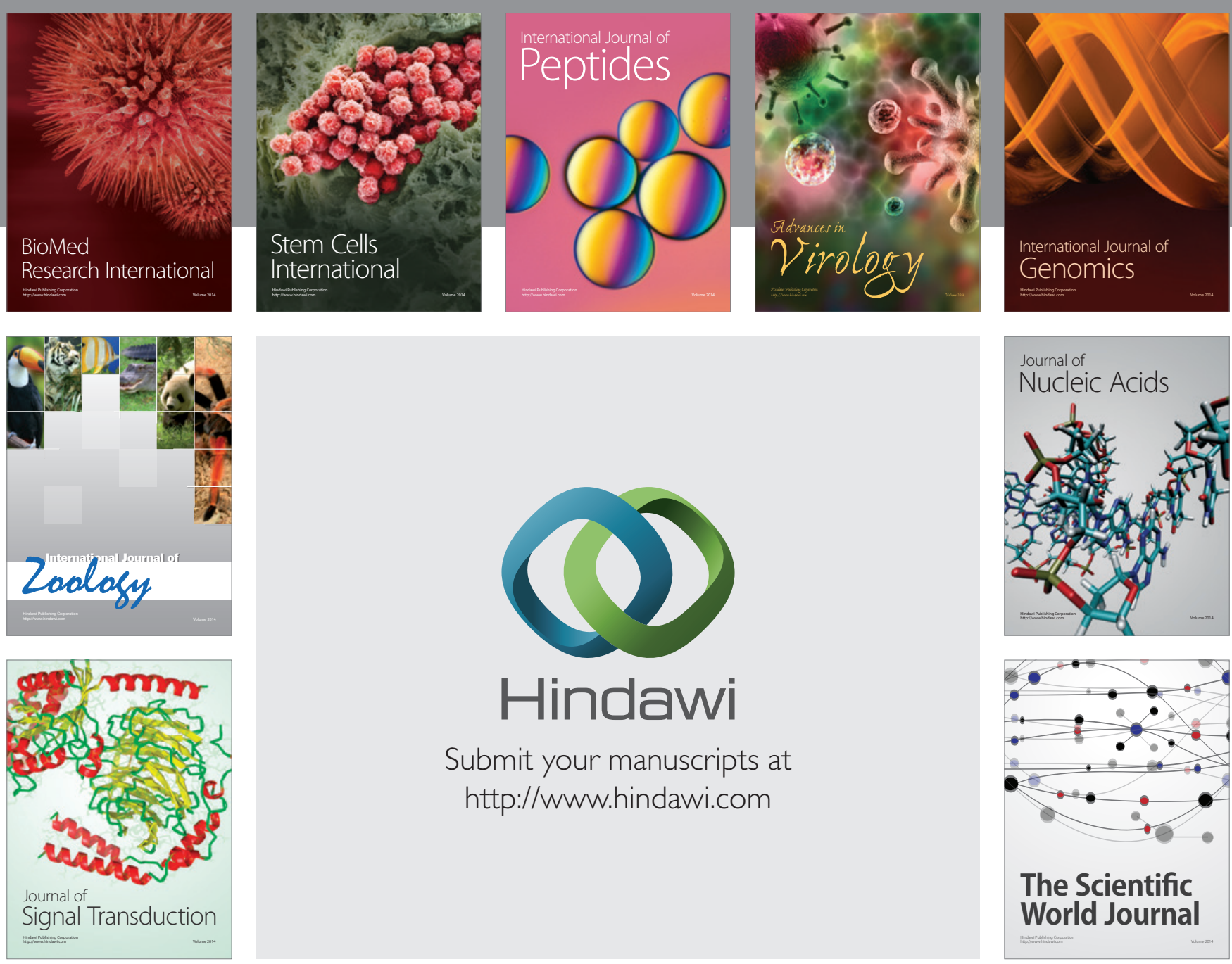

Submit your manuscripts at

http://www.hindawi.com
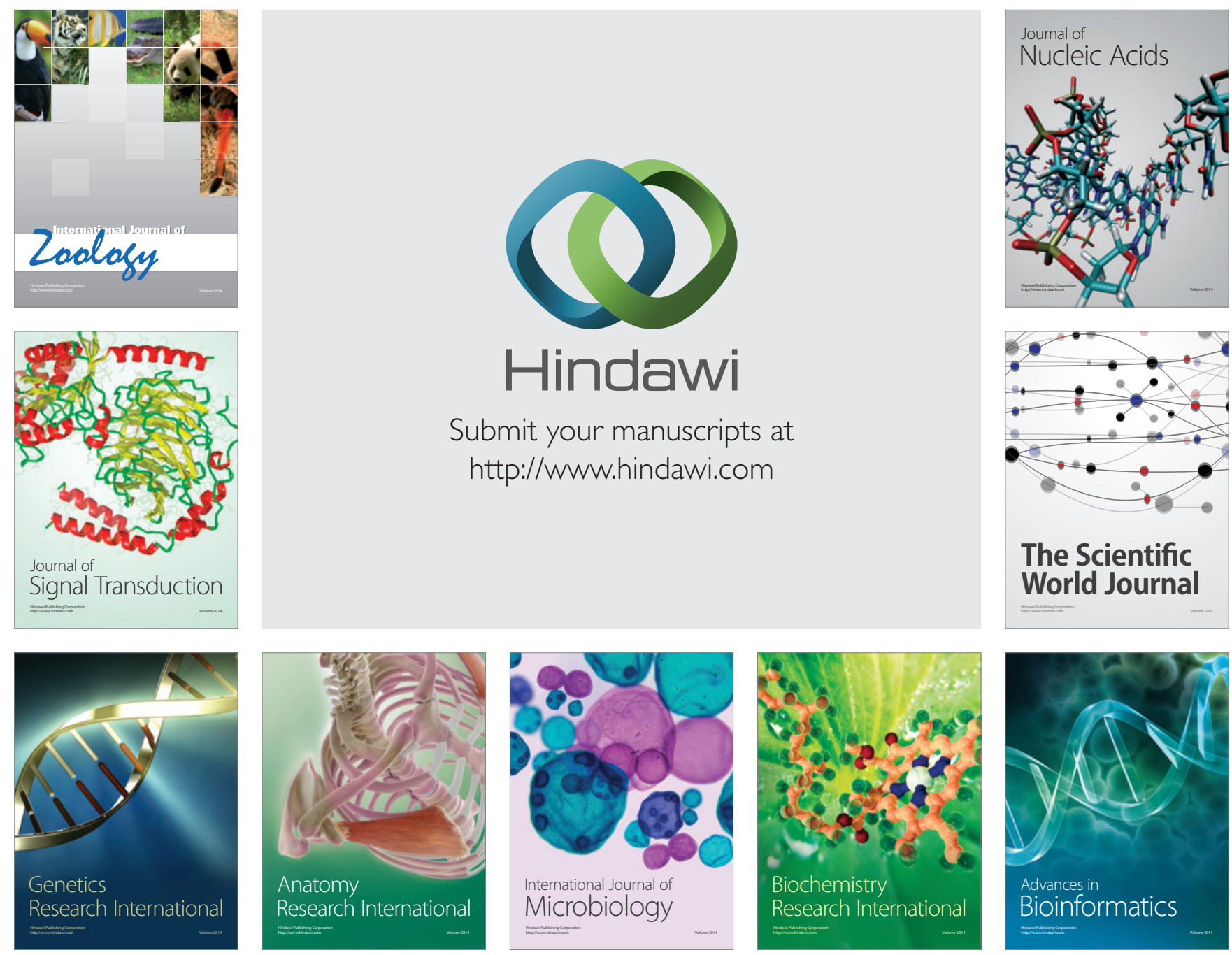

The Scientific World Journal
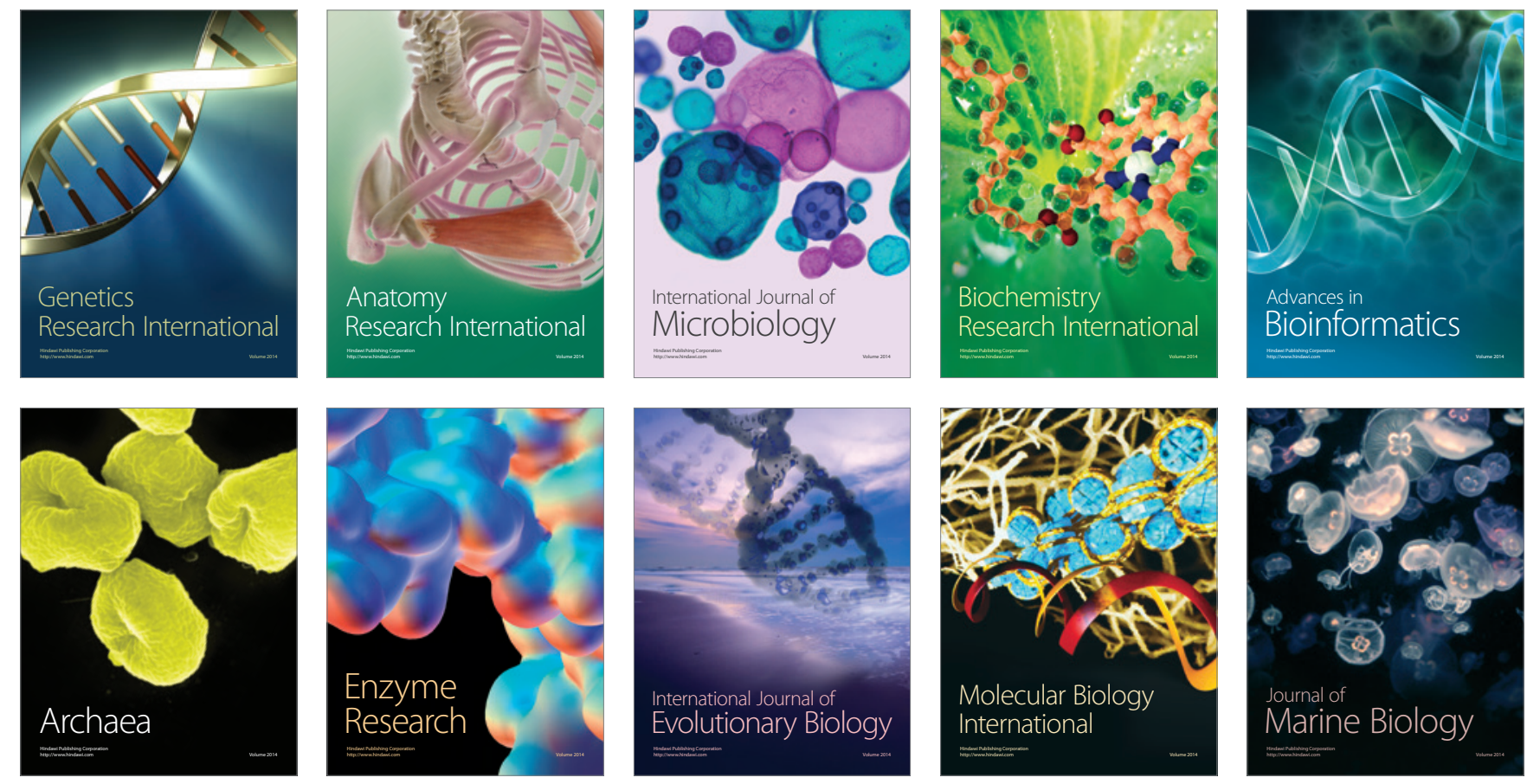